\title{
TRIZ directed evolution for automobile fuel
}

\begin{abstract}
Recently, Global Warming effect and Green House Gases (GHG) emissions have become one of the main concern for environment that principally come from the exhaust of fossil fuel combustion process (i.e. coal, crude oil, and natural gas). Electric Vehicles (EVs) industry has started taking the lead and showing significant competition in the market via Plug-in Hybrid Electric Vehicle (PHEV) and fully Battery Electric Vehicle (BEV) over the conventional fossil fuel powered vehicles which are going to ban (prohibit) within coming two decades as officially announced by many of global countries. Battery is the backbone of this evolution and it encourages many researchers and scientists to expedite their studies, experimental tests to discover the best reliable, sustainable, and safe resource of energy to meet the customers' (vehicles users) values, satisfactions and expectations. This study aims to scientifically predict and analyze the future battery generation that last longer up to $(500 \mathrm{~km})$ with improved charging time (less than $30 \mathrm{~min}$ ). A systematic evolution method called TRIZ (Theory of Inventive Problem Solving) was used in this paper to link the historical data with present timeline in order to improve the main characteristics of the battery (e.g. energy density, durability, charging time and safety). TRIZ has variety of inventive tools ( 9 Windows, S - Curve and Function Analysis), these tools are efficiently assist to predict and achieve the next generation of the future battery. By using the tools of Directed Evolution (DE) and utilizing Level of Innovation Domains, battery development is going to be deeply illustrated. Finally, logical recommendations were proposed to those personnel in charge to move forward to approach the future battery system with targeted features and characteristics.
\end{abstract}

Keyword: Battery Management System (BMS); Directed Evolution; Greenhouse Gases (GHG); Theory of Inventive Problem Solving (TRIZ) 